\title{
Vitreous intercellular adhesion molecule 1 in uveitis complicated by retinal detachment
}

\author{
Lynne Webster, Ros M Stanbury, Anthony H Chignell, G Astrid Limb
}

\begin{abstract}
Aims-The vitreous levels of soluble intercellular adhesion molecule 1 (sICAM-1) were investigated in uveitic eyes undergoing vitrectomy for retinal detachment (RD) or other complications, and the presence of this molecule was related to disease activity and vitreous levels of the cytokine tumour necrosis factor $\alpha(\mathrm{TNF} \alpha)$, known to upregulate ICAM-1 expression on various cells.
\end{abstract}

Methods-Vitreous and serum samples from 23 patients with either active or quiescent uveitis undergoing retinal surgery were examined for the levels of immunoreactive sICAM-1 and TNF $\alpha$ by ELISA methods, and for the presence of biologically active TNF $\alpha$. Vitreous from nonuveitic eyes with rhegmatogenous retinal detachment (RRD), macular holes or cadaveric eyes were used as controls.

Results-As a whole, vitreous from uveitic eyes complicated or uncomplicated by RRD contained significantly higher levels of SICAM-1 than vitreous from nonuveitic eyes with RRD alone $(p<0.0005)$, eyes with macular holes $(p<0.0001)$, or normal cadaveric vitreous $(p<0.0001)$. The proportion of vitreous containing $>20$ ng/ml sICAM-1 ( $>$ four times the normal values) was significantly higher in eyes with uveitis complicated by RRD than in those eyes without RRD (Fisher's test, $p=$ 0.02), and although levels of SICAM-1 were higher in eyes with active uveitis than in those with quiet disease $(\mathbf{p}<0.02)$, this could not be dissociated from the increase caused by RRD. There was a relation between the vitreous levels of sICAM-1 and those of immunoreactive TNFa (Spearman's correlation coefficient; $r=0.601, p=0.006$ ), but not between the vitreous levels of SICAM-1 and those of biologically active TNF $\alpha$. Conclusion-Increased vitreous SICAM-1 levels and the association of this molecule with the presence of immunoreactive TNF $\alpha$ in uveitic eyes confirm the operation of cytokine mediated vascular reactions at the blood-retinal barrier during the development of this condition. The persistence of high vitreous levels of SICAM-1 in eyes with uveitis complicated by RRD despite previous immunosuppression may indicate a low rate of clearance of inflammatory molecules from the vitreous cavity and an exacerbation of the existing inflammatory process by the retinal detachment itself. (Br f Ophthalmol 1998;82:438-443)
Uveitis is a major cause of visual impairment and blindness, which presents clinically either as an idiopathic disease or linked to a systemic disorder such as Behçet's disease or sarcoidosis. ${ }^{1}$ Conventional therapy for uveitis relies on the use of steroids or other immunosuppressive agents to remove inflammatory cells from the vitreous and reduce vitreous opacity. However, when individuals do not respond to this treatment or when other complications arise, such as rhegmatogenous retinal detachment (RRD), adjunctive vitreoretinal surgery is necessary for treatment of this condition. $^{2}$

Cytokines and adhesion molecules have been implicated in the pathogenesis of uveitis ${ }^{3-5}$ and they constitute important elements of the classic inflammatory response. ${ }^{6}$ Evidence for involvement of these molecules in the pathogenesis of this condition derives from various experimental and clinical studies. Intravitreal injection of tumour necrosis factor $\alpha(\mathrm{TNF} \alpha)$ induces uveitis in Lewis rats, ${ }^{8}$ while mRNA coding for $\mathrm{TNF} \alpha$ and other cytokines is observed during the initial and acute stages of endotoxin induced uveitis. ${ }^{9-11} \mathrm{TNF} \alpha$ may be found in vitreous from patients with uveitis ${ }^{3}$ and lipopolysaccharide induced production of this cytokine is significantly higher in individuals with active disease when compared with healthy subjects. ${ }^{12} 13$

Upregulation of the intercellular adhesion molecule 1 (ICAM-1) constitutes an important mechanism by which leucocytes are recruited into the site of inflammation. ${ }^{6}$ This molecule is constitutively expressed on vascular endothelial cells ${ }^{14}$ and retinal pigment epithelium (RPE) ${ }^{15}$ among other cells from the eye, and its expression is enhanced by inflammatory cytokines, including TNFa. ${ }^{4}{ }^{16}$ High concentrations of soluble ICAM-1 (sICAM-1) are found in vitreous from eyes with RRD complicated or uncomplicated by proliferative vitreoretinopathy (PVR $)^{18}$ and increased serum levels of this molecule in patients with retinal vasculitis directly correlate with remission or relapse of the disease. ${ }^{19-21}$

Although cytokines and adhesion molecules have been implicated in the pathogenesis of uveitis $^{3-5} 22$ and in complications of RRD, at present there is only evidence for the presence of pro-inflammatory cytokines in vitreous from eyes with uveitis. $^{3}$ Moreover, there is no knowledge of the presence or significance of sICAM-1 in vitreous from eyes with uveitis complicated or uncomplicated by RRD. On this basis we determined the levels of SICAM-1 in vitreous from patients undergoing vitreoretinal surgery for treatment of uveitic complications, 
Table 1 Clinical details of patients with uveitis

\begin{tabular}{|c|c|c|c|c|c|}
\hline Lab No & $\operatorname{Sex}$ & Age & Uveitis entities and systemic associations & Reason for vitrectomy & $\begin{array}{l}\text { Uveitis status at } \\
\text { time of surgery }\end{array}$ \\
\hline 117 & $M$ & 38 & Idiopathic posterior uveitis & RRD & Active \\
\hline 124 & $\mathrm{~F}$ & 35 & Ankylosing spondylitis & Vitreous opacity & Quiet \\
\hline 133 & M & 62 & Idiopathic posterior uveitis & TRD & Quiet \\
\hline 148 & $\mathrm{~F}$ & 41 & Sarcoidosis & RRD & Active \\
\hline 170 & M & 29 & Seronegative arthritis & RRD & Quiet \\
\hline 229 & $\mathrm{M}$ & 36 & Heterochromic cyclitis & Vitreous opacity & Quiet \\
\hline 240 & M & 75 & Viral retinal necrosis & RRD & Active \\
\hline 288 & M & 50 & Sarcoidosis & Macular pucker & Quiet \\
\hline 290 & $\mathrm{~F}$ & 17 & Toxocara & RRD & Active \\
\hline 302 & $\mathrm{~F}$ & 24 & Toxoplasmosis & Macular pucker & Quiet \\
\hline 339 & $\mathrm{M}$ & 25 & Sarcoidosis & RRD & Quiet \\
\hline 360 & $\mathrm{M}$ & 59 & Tuberculosis & Vitreous haemorrhage & Quiet \\
\hline 406 & $\mathrm{~F}$ & 28 & Viral retinal necrosis & RRD & Quiet \\
\hline 409 & $\mathrm{~F}$ & 32 & Idiopathic posterior uveitis & Vitreous haemorrhage & Quiet \\
\hline 454 & M & 28 & Ulcerative colitis & Vitreous opacity & Active \\
\hline 466 & $\mathrm{~F}$ & 40 & Tuberculosis & TRD & Quiet \\
\hline 685 & $\mathrm{~F}$ & 46 & Idiopathic posterior uveitis & Vitreous opacity & Quiet \\
\hline 687 & $\mathrm{~F}$ & 56 & Idiopathic posterior uveitis & RRD & Active \\
\hline 712 & $\mathrm{M}$ & 32 & Toxoplasmosis & Vitreous opacity & Quiet \\
\hline 739 & M & 26 & Idiopathic posterior uveitis & Vitreous haemorrhage & Quiet \\
\hline 763 & M & 56 & Idiopathic posterior uveitis & RRD & Active \\
\hline 771 & M & 55 & Idiopathic posterior uveitis & RRD & Quiet \\
\hline 774 & M & 36 & Toxoplasmosis & RRD & Active \\
\hline
\end{tabular}

$\mathrm{RRD}=$ rhegmatogenous retinal detachment; $\mathrm{TRD}=$ traction retinal detachment.

and examined the relation between the levels of this molecule and those of immunoreactive and biologically active $\mathrm{TNF} \alpha$. We also investigated the effect of retinal detachment on the vitreous expression of these molecules in uveitic eyes.

\section{Patients and methods}

Vitreous and serum specimens from 23 patients with uveitis undergoing vitrectomy for treatment of vitreous opacity or retinal detachment were investigated. Eight of the patients presented with idiopathic uveitis while the remaining 15 patients presented with uveitis associated with systemic diseases. Seventeen of the patients were on corticosteroids, either prednisolone or dexamethasone, one patient was on cyclophosphamide, and five were on no medication before surgery. The disease status of uveitis assessed by a clinician at the time of surgery (that is, active or quiet disease), other diseases associated with the condition, and retinal features, are listed in Table 1. All

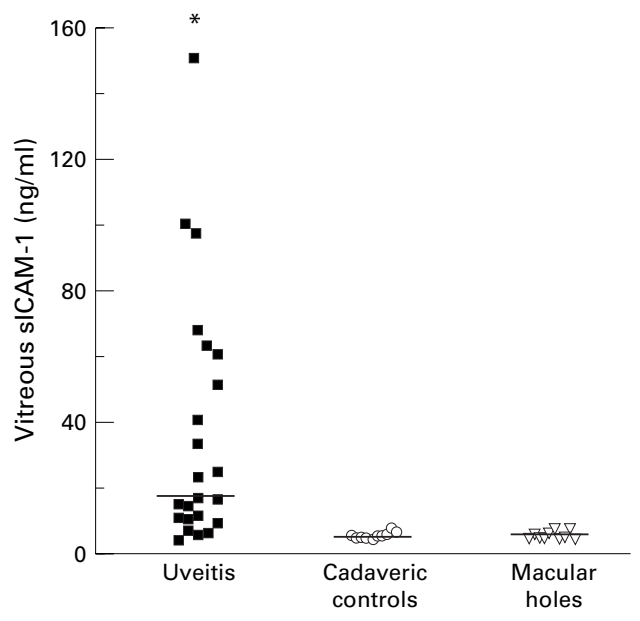

Figure 1 Levels of sICAM-1 in vitreous from eyes with uveitis complicated or uncomplicated by RD are significantly higher than in control cadaveric vitreous (Mann-Whitney U test, $\left.{ }^{\star} p<0.0001\right)$ and vitreous from eyes with macular holes (Mann-Whitney $U$ test, $\left.{ }^{*} p<0.0001\right)$. The bars represent median values. individuals in the study had uveitis before development of retinal detachment and none of the patients had proliferative retinopathy at the time of surgery. Control vitreous samples were obtained from 36 patients without uveitis or systemic disease undergoing surgery for RRD and from 10 patients undergoing surgery for macular holes. Cadaveric vitreous samples obtained within $7-18$ hours post mortem from 10 individuals with no known ocular or systemic inflammatory disease were used as normal controls. Vitreous and serum samples were stored at $-70^{\circ} \mathrm{C}$ until use.

MEASUREMENT OF TNF $\alpha$ AND ICAM-1

Commercially available ELISA kits (R\&D Systems) were used for the detection of soluble ICAM-1 and TNF $\alpha$. Vitreous and serum dilutions ( 1 in 10 and 1 in 20 respectively) in kit diluent were used for the assay, which was performed according to the manufacturer's instructions. The coloured product was measured photometrically with test and reference readings of $450 \mathrm{~nm}$ and $620 \mathrm{~nm}$ respectively on a Dynatech MR5000 plate reader. Unknown concentrations of sICAM-1 and $\mathrm{TNF} \alpha$ were determined from dose-response curves of standard preparations.

DETECTION OF BIOLOGICALLY ACTIVE TNF $\alpha$ Biologically active $\mathrm{TNF} \alpha$ was measured by a cytotoxic assay using the $\mathrm{TNF} \alpha$ sensitive murine fibrosarcoma cell line WEHI-164-32. ${ }^{23}$ Briefly, $2 \times 10^{4}$ cells in $100 \mu$ of RPMI $+5 \%$ FCS medium were incubated overnight in a 96 well plate. This was followed by addition of $100 \mu \mathrm{l}$ of standard or sample dilutions in the same medium containing $200 \mathrm{ng}$ actinomycin $\mathrm{D}$ and further incubation for 24 hours at $37^{\circ} \mathrm{C}$. MTS (3-(4,5-dimethylthiazol-2-yl)-5-(3-carboxymethoxyphenyl)-2-(4-sulphophenyl)-2H-tetrazolium solution) with $0.05 \%$ phenazine methosulphate (Promega, UK) was then added to produce a colour reaction as a direct measure of the number of viable cells. Optical density was measured with test and reference readings of $490 \mathrm{~nm}$ and $620 \mathrm{~nm}$ respectively on 


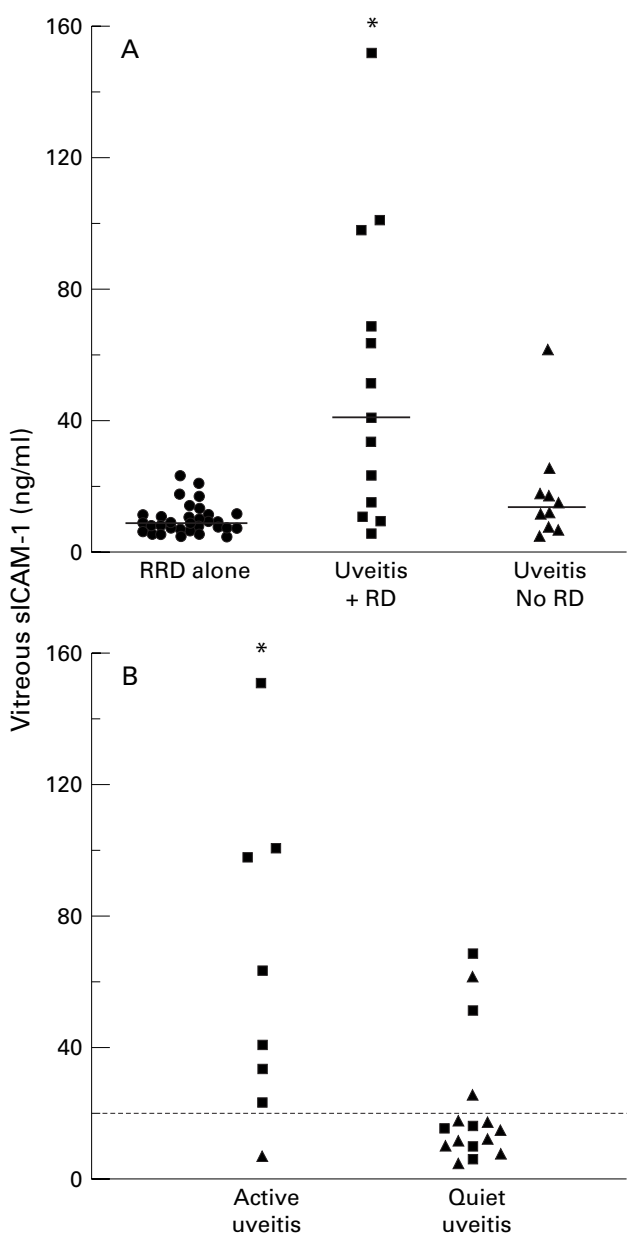

Figure 2 (A) Levels of sICAM-1 in vitreous from patients with uveitis complicated by retinal detachment (-); patients with other uveitis complications but without retinal detachment $(\boldsymbol{\Delta})$ and patients with rhegmatogenous retinal detachment alone $(\bullet)$. (Mann-Whitney $U$ test: uveitis with $R D$ v uveitis without $R D{ }^{*} p<0.02$; uveitis with $R D$ $v$ RRD alone $\left.{ }^{*} p<0.0001\right)$. The bars represent median values. (B) Levels of sICAM-1 in vitreous from eyes with active uveitis compared with vitreous from eyes with quiet disease. (Mann-Whitney $U$ test $\left.{ }^{*} p<0.02\right)$. Uveitis patients with $R D(\mathbf{\square})$ and without $R D(\mathbf{\Delta})$. The dotted line represents $20 \mathrm{ng} / \mathrm{ml}$ sICAM-1.

Table 2 Statistical analysis of uveitis patient subgroups

\begin{tabular}{llll}
\hline Uveitis subgroup & No* & $\begin{array}{l}\text { Median } \\
(\mathrm{ng} / \mathrm{ml})\end{array}$ & Range $(\mathrm{ng} / \mathrm{ml})$ \\
\hline Active uveitis: & & & \\
$\quad$ with RD & $(7)$ & 63.37 & $23.28-150.78$ \\
$\quad$ without RD & $(1)$ & 6.44 & 6.44 \\
$\begin{array}{l}\text { Quiet uveitis: } \\
\quad \text { with RD }\end{array}$ & $(6)$ & 12.91 & $5.94-68.54$ \\
$\quad$ without RD & $(9)$ & 14.40 & $4.49-60.76$ \\
$\begin{array}{l}\text { Idiopathic uveitis: } \\
\quad \text { with RD }\end{array}$ & $(5)$ & 63.37 & $33.50-100.54 \dagger$ \\
$\quad$ without RD & $(3)$ & 11.23 & $7.00-16.60$ \\
$\quad$ Systemic disease: & & & \\
$\quad$ with RD & $(8)$ & 19.25 & $5.94-150.78$ \\
$\quad$ without RD & $(7)$ & 14.40 & $4.49-60.76$ \\
\hline
\end{tabular}

${ }^{\star}$ Number of patients in each group.

†Fisher's test, $\mathrm{p}=0.02$, $v$ idiopathic uveitis without $\mathrm{RD}$.

a Dynatech MR5000 plate reader and the concentration of $\mathrm{TNF} \alpha$ in individual samples was calculated by extrapolation from doseresponse curves of standard preparations $(\mathrm{Na}-$ tional Institute for Biological Standards and Control, NIBSC, England).

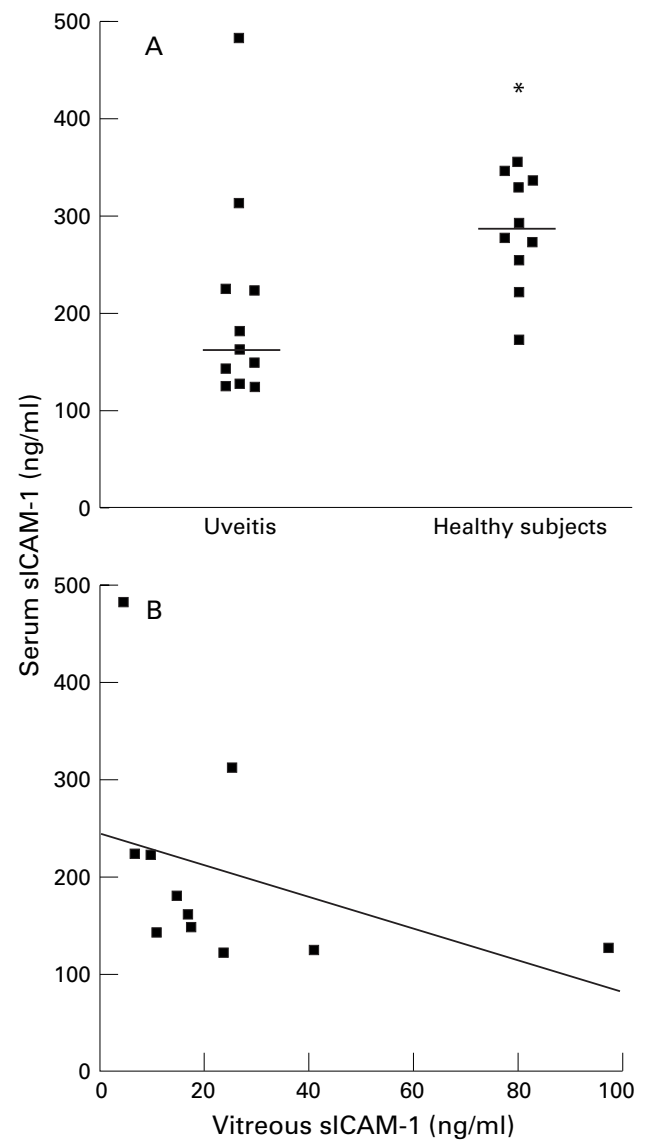

Figure 3 (A) Serum levels of sICAM-1 in patients with uveitis (at the time of vitrectomy) compared with those of sex and age matched controls. (Mann-Whitney $U$ test, $\left.{ }^{*} p<0.02\right)$. The bars represent median values. (B) Relation between sICAM-1 levels in serum and vitreous from uveitis patients (Mann-Whitney $U$ test, $p<0.25, r=-0.39$ ). The solid line represents the linear regression curve of best fit.

STATISTICAL ANALYSIS OF THE RESULTS

The significance of difference between corresponding groups of observations was evaluated by the Mann-Whitney $U$ test and by $\chi^{2}$ analysis, after constructing $2 \times 2$ contingency tables. Acceptable significance was recorded when $\mathrm{p}$ values were $<0.05$. Spearman's rank correlation coefficient on the logged data was used to determine the relation between vitreous levels of sICAM-1 and TNF $\alpha$.

\section{Results}

Figure 1 shows that vitreous levels of sICAM-1 as a whole were significantly higher in the 23 patients with uveitis (median, 17.19; range, 4.49-150.78 ng/ml) when compared with normal cadaveric vitreous (median, 5.18; range, 4.17-7.35 ng/ml; Mann-Whitney U test $\mathrm{p}<$ 0.0001 ) or vitreous from eyes with macular holes (median, 4.83; range, 4.41-7.68 ng/ml, $\mathrm{p}<0.0001)$. Vitreous specimens from eyes with uveitis complicated by RRD (13 rhegmatogenous RD and two traction RD (TRD)) (median, 40.87; range, 5.94-150.78 ng/ml) contained significantly higher levels of sICAM-1 than those from non-uveitic eyes with RRD alone (median, 8.69; range, 4.89$23.53 \mathrm{ng} / \mathrm{ml}$; Mann-Whitney U test, $\mathrm{p}<$ $0.0001)$ or uveitic eyes with other complications (median, 13.06; range, 4.49-60.76 ng/ml, 
Table 3 Levels of immunoreactive TNFa and sICAM-1 in vitreous samples from eyes with uveitis

\begin{tabular}{lll}
\hline Lab No & TNFa $(\mathrm{pg} / \mathrm{ml})$ & sICAM-1 $(\mathrm{ng} / \mathrm{ml})$ \\
\hline 117 & ND & 33.50 \\
124 & 5.44 & 11.71 \\
133 & 7.28 & 68.54 \\
148 & ND & 23.28 \\
170 & 4.32 & 15.22 \\
229 & ND & 14.40 \\
240 & 32.26 & 97.78 \\
288 & 6.14 & 24.97 \\
290 & 25.64 & 40.87 \\
302 & 3.56 & 4.49 \\
339 & 2.52 & 5.94 \\
360 & 7.02 & 17.19 \\
406 & 3.32 & 9.46 \\
409 & 3.84 & 16.60 \\
454 & 4.48 & 6.44 \\
466 & 3.02 & 10.60 \\
685 & 3.75 & 7.00 \\
687 & 3.99 & 100.54 \\
712 & 3.22 & 60.76 \\
739 & 6.70 & 11.23 \\
763 & 9.30 & 63.37 \\
771 & 10.03 & 51.30 \\
774 & ND & 150.78 \\
\hline
\end{tabular}

$\mathrm{ND}=$ not done

$\mathrm{p}<0.04$ ) (Fig 2A). Comparison of the vitreous levels of this molecule between active and quiet disease showed that the highest SICAM-1 concentrations were present in eyes with active uveitis (Mann-Whitney U test, $\mathrm{p}<0.02$ ) (Fig 2B). All seven vitreous samples from eyes with active uveitis complicated by RRD contained $>20 \mathrm{ng} / \mathrm{ml}$ sICAM-1 ( > four times the normal levels), in contrast with two of six vitreous from eyes with quiet uveitis complicated by RRD or traction retinal detachment (Fisher's test, $\mathrm{p}=$ 0.02) (Fig 2B)

For analysis of the data, patients were divided into subgroups consisting of two possible contributory factors towards raised levels of sICAM-1 as follows: (1) active uveitis with and without RD; (2) quiet uveitis with and without $\mathrm{RD}$; (3) idiopathic uveitis with and without $\mathrm{RD}$; and (4) uveitis with systemic disease with and without RD. As shown in Table 2, although the median values and ranges appear to be higher in the groups with $\mathrm{RD}$, the only statistically significant difference was observed in the group of patients with idiopathic uveitis complicated by $\mathrm{RD}$ when compared with patients with idiopathic uveitis without RD (Fisher's test, $\mathrm{p}=0.02$ ).

Figure $3 \mathrm{~A}$ shows that serum levels of sICAM-1 in patients with uveitis were significantly lower at the time of vitrectomy (MannWhitney $U$ test, $p<0.02$ ) than those in serum of healthy subjects matching sex and age of the patients. There was no relation between vitreous and serum levels of sICAM-1 $(r=-0.39, \mathrm{p}$ $<0.25$ ) in the whole group of patients (Fig 3B).

Biologically active $\mathrm{TNF} \alpha$ was not detected in any of the vitreous samples investigated. However, immunologically detectable $\mathrm{TNF} \alpha$ was found in concentrations ranging between 2 and $33 \mathrm{pg} / \mathrm{ml}$ in all vitreous from uveitic eyes (Table 3). Interestingly, there was an association between the vitreous levels of SICAM-1 and those of immunologically detectable $\mathrm{TNF} \alpha$ (Spearman's correlation coefficient; $r=$ $0.60, \mathrm{p}<0.006$ ) (Fig 4). Vitreous levels of sICAM-1 were not related to disease status,

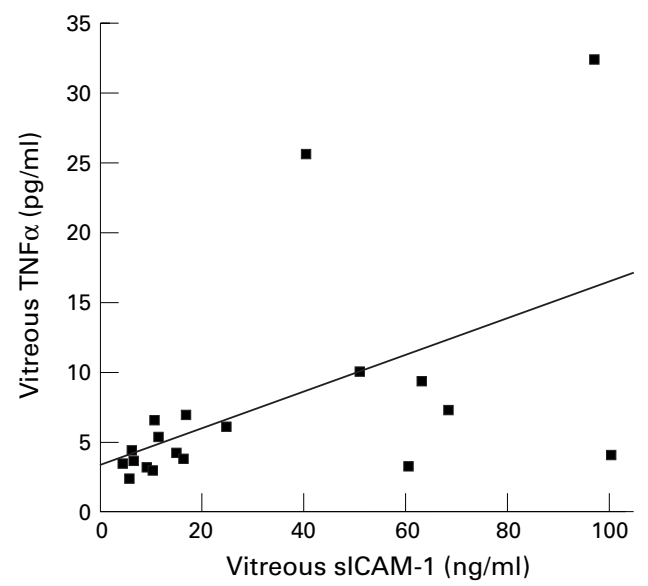

Figure 4 Relation between levels of sICAM-1 and immunologically detectable TNFa in vitreous from 19 patients with uveitis. The solid line represents the linear regression curve of best fit.

medication at the time of vitrectomy, or association of uveitis with systemic disease.

\section{Discussion}

The present observations showed that vitreous from eyes with uveitis complicated or uncomplicated by $\mathrm{RD}$ contained higher levels of sICAM-1 than disease control vitreous (RRD alone or macular holes) and normal cadaveric vitreous $(p<0.0001)$. Higher vitreous levels of this molecule were found in eyes with active disease and retinal detachment than in those with quiet disease and other complications $(p<0.02)$, as well as in eyes with idiopathic uveitis complicated by $\mathrm{RD}$ when compared with patients with idiopathic uveitis without $\mathrm{RD}$. Interestingly, all seven vitreous specimens from eyes with active uveitis complicated by $\mathrm{RD}$ contained $>20 \mathrm{ng} / \mathrm{ml}$ sICAM-1 (four times the normal levels), in contrast with two of six samples of vitreous from eyes with quiet disease complicated by RRD or TRD (Fisher's test, $p=0.02$ ). Immunologically detectable but not biologically active $\mathrm{TNF} \alpha$ was also observed in all the vitreous specimens investigated and immunoreactive $\mathrm{TNF} \alpha$ levels correlated with those of sICAM-1.

Expression of ICAM-1 by various cells of the retina, choroid, and leucocytes has been shown in vivo and in vitro, and activation of these cells with pro-inflammatory cytokines such as $\mathrm{TNF} \alpha$ induces increased expression and release of this molecule. Since upregulation of ICAM-1 is often accompanied by release of its extracellular portion into the surrounding tissues and fluids, it is likely that the sICAM-1 found in vitreous from eyes with uveitis is derived from various retinal cells, including retinal vascular endothelium, RPE cells, and leucocytes among others. The findings that a higher proportion of uveitic eyes complicated by $\mathrm{RD}$ contained raised levels of SICAM-1 suggests that mechanical breakdown of the blood-retinal barrier may amplify the inflammatory process in the uveitic eye, in a similar way to that seen in proliferative vitreoretinopathy, a complication of rhegmatogenous retinal detachment. ${ }^{18}$ The high vitreous levels 
of sICAM-1 observed in uveitic eyes with RD can not be ascribed entirely to the retinal detachment itself, as non-uveitic eyes with RRD alone contained similar vitreous sICAM-1 levels than those of uveitic eyes without RD. Since upregulation of ICAM-1 on activated endothelium constitutes an important mechanism by which leucocytes are recruited into the inflammatory site, it is possible that high expression of SICAM-1 on the retinal endothelium may promote the recruitment and accumulation of leucocytes and local inflammatory cells and hence may be responsible for the chronicity of this process.

Unlike a report by others that serum levels of sICAM-1 are increased in patients with active uveitis ${ }^{19}$ we did not observe enhanced levels of this molecule in the serum of patients with uveitis undergoing vitrectomy. This might be due to decreased inflammation caused by systemic steroids routinely administered before retinal surgery.

$\mathrm{TNF} \alpha$ is a pro-inflammatory cytokine with important autocrine and paracrine functions. It stimulates mononuclear phagocytes to produce other cytokines, induces and enhances the expression of adhesion molecules in various cell types, and increases vascular permeability. ${ }^{16}$ The biologically active form of $\mathrm{TNF} \alpha$ consists of a trimer of three $17 \mathrm{kD}$ subunits which is inactivated by enzymatic fragmentation into monomers and dimers. Since all forms of active and inactive $\mathrm{TNF} \alpha$ can be detected by immunoassay, the present findings that immunoreactive but not biologically active $\mathrm{TNF} \alpha$ was detected in vitreous suggest that $\mathrm{TNF} \alpha$ may have been produced locally during the initiation of the uveitic process but later inactivated by natural inhibitors of inflammation. ${ }^{24}$ The presence of $\mathrm{TNF} \alpha$ in vitreous from eyes with uveitis is of special significance as this cytokine may be largely responsible for the initiation of the inflammatory cascade that leads to the accumulation of inflammatory cells into the eye and hence to the complications often seen in this condition such as vitreous opacity, vitreous detachment, and retinal detachment. ${ }^{25}$ Implication of TNF $\alpha$ in the pathogenesis of uveitis is supported by findings that intravitreal administration of this cytokine in rabbits increases aqueous protein concentration and induces influx of polymorphonuclear granulocytes into the anterior chamber, ${ }^{26}$ and that intravitreal but not systemic administration of this cytokine causes uveitis in rats. ${ }^{8}$ Further evidence for the implication of $\mathrm{TNF} \alpha$ in uveitic disease is given by observations that aqueous cells from human uveitic eyes express mRNA coding for TNF $\alpha$ and that ocular tissues from eyes with this condition stain strongly for $\mathrm{TNF} \alpha{ }^{3}{ }^{8}$ In addition, lipopolysaccharide induced $\mathrm{TNF} \alpha$ production in whole blood is significantly enhanced in patients with active uveitis compared with normal subjects. ${ }^{12}$

Increased vitreous levels of sICAM-1 and the relation between the presence of this molecule and that of immunoreactive $\mathrm{TNF} \alpha$ in uveitic eyes clearly indicate the operation of cytokine mediated vascular reactions at the blood-retinal barrier during the development of this condition. Persistence of high vitreous levels of sICAM-1 in uveitic eyes complicated by RRD, despite administration of immunosuppressive drugs, may indicate both a low rate of clearance of this molecule from the eye cavity, and an exacerbation of the existing inflammatory process by the retinal detachment itself. Better understanding of the mechanisms that promote the release of soluble adhesion molecules within the retinal microenvironment may aid in the design of new therapeutic approaches for the control of the inflammatory process caused by uveitic disease and its complications. We thank The Guide Dogs for the Blind Association and the
trustees of The Gift of Thomas Pocklington for their invaluable trustees of The Gift of Thomas Pocklington for the
support, and to Mr M Stanford for clinical advice.

1 Gery I, Nussenblatt RB. Immunological basis of uveitis. In: Pepose JS, Holland GN, Wilhelmus KR, eds. Ocular infection and immunity. London: Mosby, 1996:141-56.

2 Rocha G, Baines MG, Deschenes J. The immunology of the eye and its systemic interactions. Crit Rev Immunol 1992;12:81-100.

3 Franks WA, Limb GA, Stanford MR, et al. Cytokines in human intraocular inflammation. Curr Eye Res 1991;11: 187-91.

4 Kijlstra A. The role of cytokines in ocular inflammation. $\mathrm{Br}$ f Ophthalmol 1994;78:885-6.

5 Whitcup SM, Chan CC, Li Q, Nussenblatt RB. Expression of cell adhesion molecules in posterior uveitis. Arch Ophthalmol 1992;110:662-6.

6 Cronstein BN, Weissmann G. The adhesion molecules of inflammation. Arthritis Rheum 1993;36:147-57.

7 Akira S, Hirano T, Taga T, Kishimoto T. Biology of multifunctional cytokines: IL-6 and related molecules (IL-1 and TNF). FASEB f 1990;4:2860-7.

8 De Vos AF, Van Haren MAC, Verhagen C, Hoekzema R, Kijlstra A. Tumour necrosis factor-induced uveitis in the Lewis rat is associated with intraocular interleukin 6 production. Exp Eye Res 1995;60:199-207.

9 De Vos AF, Klaren VNA, Kijlstra A. Expression of multiple cytokines and interleukin-1 receptor antagonist in the uvea and retina during endotoxin-induced uveitis in the rat. Invest Ophthalmol Vis Sci 1994;35:3873-83.

10 Planck SR, Huang XN, Robertson JE, Rosenbaum JT. Cytokine mRNA levels in rat tissues following systemic endotoxin treatment. Invest Ophthalmol Vis Sci 1994;35: 924-30.

11 Yoshida M, Yoshimura N, Hangai M, Tanihara H, Honda Y. Interleukin- $1 \alpha$, interleukin- $1 \beta$ and tumour necrosis factor gene expression in endotoxin induced uveitis. Invest Ophthalmol Vis Sci 1994;35:1107-13.

12 Ellis BA, Patel SY, Stanford MR, et al. Tumour necrosis factor production by lipopolysaccharide stimulated peripheral blood mononuclear cells from patients with retinal vasculiblood mononuclear cells from patien
tis. Regional Immunol 1995;6:27-30.

13 Chofflon M, Juillard C, Juillard P, Gauthier G, Grau GE. Tumor necrosis factor $\alpha$ production as a possible predictor of relapse in patients with multiple sclerosis. Eur Cytokine Netw 1992;3:523-31

14 Mackay CR, Imhof BA. Cell adhesion in the immune system. Immunol Today 1993;14:99-102.

15 Elner SG, Elner VM, Pavilack MA, et al. Modulation and function of intercellular adhesion molecule-1 (CD54) on 200-11.

16 Camussi G, Albano E, Tetta C, Bussolino F. The molecular action of tumour necrosis factor- $\alpha$. Eur $\mathcal{f}$ Biochem 1991;202:3-14.

17 Gearing AJH, Newman W. Circulating adhesion molecules in disease. Immunol Today 1993;14:506-12.

18 Limb GA, Chignell AH, Cole CJ, et al. Vitreous levels of intercellular adhesion molsecule-1 (ICAM-1) in proliferative vitreoretinopathy. Invest Ophthalmol Vis Sci 1997;38: 1043-8.

19 Arocker-Mettinger EA, Steurer-Georgiew L, Steurer M, et al. Circulating ICAM-1 levels are elevated in the serum of uveitis patients. In: Dernouchamps JP, Verougstraete C, Caspers-Velu L, Tassignon MJ, eds. Recent advances in uveitis. Amsterdam/New York: Kugler, 1993:95-101.

20 Zaman AG, Edelsten C, Stanford MR, et al. Soluble intercellular adhesion molecule-1 (sICAM-1) as a marker of disease relapse in idiopathic uveoretinitis. Clin Exp Immunol 1994;95:60-5.

21 Palmer HE, Zaman AG, Ellis BA, et al. Longitudinal analysis of soluble intercellular adhesion molecule 1 in retina vasculitis patients. Eur F Clin Invest 1996;26:686-91. 
22 Wakefield D, Lloyd A. The role of cytokines in the pathogenesis of inflammatory eye disease. Cytokine 1992;4: $1-5$.

23 Espevik T, Nissen-Meyer J. A highly sensitive cell line, WEHI 164 clone 13 , for measuring cytotoxic factor/tumor necrosis factor from human monocytes. F Immunol Methods 1986;95:99-105.

24 Ettehadi P, Greaves MW, Wallach D, Aderka D, Camp RDR. Elevated tumour necrosis factor-alpha $(\mathrm{TNF} \alpha)$ bio- logical activity in psoriatic skin lesions. Clin Exp Immunol 1994;96:146-51.

25 Koerner F, Messerli J, Ruggli J. Vitrectomy in 165 eyes with uveitis. In: Dernouchamps JP, Verougstraete C, CaspersVelu L, Tassignon MJ, eds. Recent advances in uveitis. Amsterdam/New York: Kugler, 1993:613-16.

26 Kulkarni PS, Srinivason BD. Cachectin:a novel polypeptide induces uveitis in the rabbit eye. Exp Eye Res 1988;46:631- 